\title{
PENGARUH KELAIKAN DAN KELENGKAPAN TERHADAP KESELAMATAN PENGEMUDI DI SEPEDA MOTOR
}

\author{
Purwatiningsih, SH, MM \\ Dosen STTD \\ Jl. Raya Setu No. 89, Cibuntu, \\ Cibitung, Bekasi 17520 \\ Telp./Fax : (021) 8254640
}

\author{
Abadi Sastrodiyoto, SH, MH \\ Dosen STTD \\ J1. Raya Setu No. 89, Cibuntu, \\ Cibitung, Bekasi 17520 \\ Telp./Fax : (021) 8254640
}

\author{
Subarto, ATD, MM \\ Dosen STTD \\ Jl. Raya Setu No. 89, Cibuntu, \\ Cibitung, Bekasi 17520 \\ Telp./Fax : (021) 8254640
}

\author{
Juliaman Pangaribuan, MSi \\ Dosen STTD \\ Jl. Raya Setu No. 89, Cibuntu, \\ Cibitung, Bekasi 17520 \\ Telp./Fax : (021) 8254640
}

\author{
Aditya Trinanda, ST \\ Instruktur STTD \\ J1. Raya Setu No. 89, Cibuntu, \\ Cibitung, Bekasi 17520 \\ Telp./Fax : (021) 8254640
}

\begin{abstract}
The development of transportation in Indonesia today in terms of number of vehicles produced and operated on the road increase sharply. It is in line with the implementation of economic development which implemented. The increasing number of vehicles operating on the road, resulting in remarkable congestion especially in big cities and the use of public transport is not optimal and yet to fulfill the needs of citizens, in addition, besides it is onsidered the amount of the cost is still too expensive in general when compared to its earnings. As a result of these conditions, then people seek the transportation that is considered easy, efficient, and low cost, which is a motorcycle.

The high usage of motorcycles makes it importance in increasing road traffic safety culture. Safety factor strongly associated with the requirements and the technical completeness of a motorcycle (roadworthy) as well as administrative requirements and completeness of motorcycle driver. The influence factors requirements and the technical completeness of motorcycles as well as administrative requirements and completeness of motorcycle driver with a very large safety, but there are other factors that influence (factors of infrastructure, human and environmental).
\end{abstract}

Keywords: Roadworthy, Motorcycle

\begin{abstract}
ABSTRAKSI
Perkembangan angkutan di Indonesia dewasa ini dari segi jumlah kendaraan yang diproduksi dan beroperasi di jalan meningkat sangat tajam.Hal tersebut sejalan dengan pelaksanaan pembangunan perekonomian yang dilaksanakan. Meningkatnya jumlah kendaraan yang beroperasi di jalan, berakibat terjadinya kemacetan yang luar biasa terutama di kota-kota besar dan penggunaan angkutan umum belum optimal dan belum dapat memenuhi kebutuhan warga masyarakat, di samping itu secara umum dirasakan masih terlalu tinggi besaran tarifnya apabila dibandingkan dengan pendapatannya.Sebagai akibat dari kondisi tersebut, maka masyarakat mencari alat transportasi yang dianggap mudah, hemat, dan berbiaya rendah, yaitu sepeda motor.

Tingginya penggunaan sepeda motor membuat pentingnya meningkatkan budaya keselamatan berlalu lintas. Keselamatan sangat terkait dengan faktor persyaratan dan kelengkapan teknis sepeda motor (laik jalan) serta faktor persyaratan administrasi dan kelengkapan pengemudi sepeda motor. Pengaruh faktor persyaratan dan kelengkapan teknis sepeda motor serta faktor persyaratan administrasi dan kelengkapan pengemudi sepeda motor dengan keselamatan sangat
\end{abstract}


besar, namun masih terdapat faktor lain yang mempengaruhi (faktor prasarana, manusia dan lingkungan).

\section{Kata Kunci: Laik Jalan, Sepeda Motor}

\section{PENDAHULUAN}

\section{A. Latar Belakang}

Untuk tahun 2014 terjadi kecelakaan lalu lintas di jalan sebanyak 95.906 kasus, dengan jumlah korban meninggal dunia sebanyak 28.97 orang. Hal ini berarti pada tahun 2014 terdapat 263 kasus kecelakaan lalu lintas dengan korban meninggal dunia sebanyak 79 orang setiap hari, yang sebagian besar adalah pengendara sepeda motor, bahkan 57\% korbannya adalah siswa SMA (Kompas, 26 Oktober 2015).

Selanjutnya sesuai data dari Polda Metro Jaya untuk jumlah sepeda motor yang terlibat dalam kecelakaan lalu lintas pada tahun 2013 sebanyak 119.560 kendaraan. Pada tahun 2014 sebanyak 108.883 dengan korban sebanyak 108.883orang.

Untuk remaja yang mengalami kecelakaan dengan sepeda motor pada tahun 2011 sebanyak 31.456 orang (18\%) dan pada tahun 2012 sebanyak 55.221 orang (28\%). Remaja yang mengalami kecelakaan dan tidak mempunyai SIM pada tahun 2011sebanyak 53.065 orang (50\%) dan pada tahun 2012 sebanyak 64.114 orang (51\%).

\section{B. Identifikasi Masalah}

Berdasarkan latar belakang tersebut di atas, dapat didentifikasi masalah sebagai berikut :

1. Sepeda motor yang beroperasi, kurang memenuhi persyaratan teknis dan laik jalan akibat tidak dilakukan perawatan secara berkala termasuk penggantian ban yang sudah gundul.

2. Sepeda motor yang beroperasi, tidak dilengkapi dengan SNTK, tidak dilengkapi pemasangan spion dengan benar/tidak ada/rusak.

3. Sepeda motor yang beroperasi, tidak dilengkapi dengan sein yang baik/mati/nyala tidak berkedip/rusak.

4. Sepeda motor yang beroperasi dengan lampu rem mati/rusak.

5. Tidak mepunyai SIM C untukmengemudikan sepeda motor.

6. Memperoleh SIM C tidak melalui prosedur.

7. Mengemudikan sepeda motor tidak memakai helm yang memenuhi SNI, sepatu, jaket yang dapat memantulkan cahaya, dan sarung tangan pelindung. 
8. Mengemudikan sepeda motor tidak sesuai dengan tata cara mengemudi yang baik/selamat, karena tidak memahami mengenai rambu lalu lintasserta tanda-tanda lain sebagai aturan berlalu lintas.

9. Mengemudikan sepeda motor tidak mentaati dan mematuhi rambu-rambu lalu lintas yang dipasang.

10. Mengemudikan sepeda motor dengan ceroboh, sehingga dapat mencelakakan diri sendiri atau orang lain.

\section{Rumusan Masalah}

Berdasarkan jumlah kecelakaan lalu lintas yang terjadi dengan jumlah korban jiwa yang cukup tinggi tersebut, maka perlu dilakukan penelitian bagi pengguna sepeda motor, dengan rumusan masalah sebagai berikut :

1. Bagaimana persyaratan teknis dan laik jalan untuk sepeda motor yang dipergunakan sehingga dapat menngkatkan keselamatan?

2. Bagaimana kelengkapan administratif dan teknis bagi pengendara sepeda motor sehingga dapat menngkatkan keselamatan?

3. Bagaimana cara mengemudikan sepeda motor yang selamat?

\section{Batasan Masalah}

Dalam penelitian ini ruang lingkup penelitian ini dibatasihanya terkait dengan persyaratan teknis dan laik jalan sepeda motor, serta kelengkapan administratif dan teknissepeda motor. Sedangkan jenis sepeda motornya, yaitu sepeda motor roda dua tanpa rumah-rumah.

Sesuai ketentuan yang berlaku setiap kendaraan bermotor yang dioperasikan di jalan harus memenuhi persyaratan teknis dan laik jalan.

Persyaratan teknis kendaraan bermotor meliputi:

\section{Susunan.}

2.Perlengkapan.

3.Ukuran.

4. Rancangan teknis kendaaraan sesuai peruntukanya.

5.Pemuatan.

6.Penggunaan

7.Penganndengan kendaraan bermotor dan atau

8.Penempelan Kendaraan bermotor.

Persyaratan Laik Jalan kendaraan bermtor meliputi: 
1. Suara klakson.

2. Efisiensi suara.

3. Efisiensi sistem rem utama.

4. Efisiensi sistem rem parkir.

5. Kincup roda depan.

6. Suara kalkson.

7. Daya pancar dan arah sinar lampu utama.

8. Radius putar.

9. Akurasi alat penunjuk kecepatan.

10. Kesesuaian kinerja roda dan kondisi ban.

11. Kesesuaian daya mesin penggerak terhadap berat kendaraan.

\section{TINJAUAN PUSTAKA}

\section{A. Pengertian/definisi}

1. Angkutan adalah perpindahan orang dan/atau barang dari satu tempat ke tempat lain dengan menggunakan kendaraan di ruang lalu lintas jalan (PP Angkutan Jalan).

2. Angkutan umum adalah angkutan penumpang dengan sistem sewa dan atau bayar ,termasuk didalamnya pengertian angkutan umum penumpang adalah angkutan kota dengan kendaraan angkutan jalan ,kereta api,angkutan air dan angkutan udara (WARPANI 1990).

3. Kendaraan bermotor adalah setiap kendaraan yang digerakan oleh peralatan mekanik berupa mesin selain kendaraan yang berjalan di atas rel (PP Kendaraan).

4. Sepeda motor adalah kendaraan bermotor beroda dua dengan atau tanpa rumahrumah, kendaraan bermotor roda dua dengan atau tanpa kereta samping,kendaraan bermotor beroda tiga tanpa rumah-rumah (UU LLAJ).

5. Keselamatan lalu lintas dan angkutan jalan adalah suatu keadaan terhindarnya setiap orang dari resiko kecelakaan selama berlalu lintas yang disebabkan oleh manusia, kendaraan, jalan, dan/atau lingkungan (UU LLAJ).

6. Pengemudi adalah orang yang mengemudikan kendaraan bermotor di jalan yang telah memiliki surat izin mengemudi (SIM)-(UU LLAJ).

7. Lalu lintas adalah gerak kendaraan dan orang di runag lalu lintas berupa jalan dan fasilitas pendukungnya (UU LLAJ). 
8. Kecelakaan lalu lintas adalah suatu peristiwa di jalan yang tidak diduga dan tidak disengaja melibatkan kendaraan dengan atau tanpa pengguna jalan lain yang mengakibatkan korban manusia dan/atau kerugian harta benda (UU LLAJ).

9. Persyaratan teknis sepeda motor adalah persyaratan yang harus dipenuhi setiap sepeda motor yang akan dioperasikan di jalan umum yang merupakan seperangkat persyaratan yang memenuhi standar meliputi susunan, perlengkapan, ukuran, karoseri, rancangan teknis kendaraan sesuai peruntukannya, pemuatan, dan penggunaan sepeda motor.

\section{METODOLOGI PENELITIAN}

\section{A. Desain Proses Penelitian}

Lokasi kegiatan direncanakan di wilayah Kabupten Bekasi dan selanjutnya kegiatan ini direncanakan dibagi dalam empat (4) tahapan yang dimulai dari identifikasi masalah, pengumpulan data, pengolahan data dan keluaran (output), yang secara rinci dapat dijelaskan sebagai berikut :

1. Identifikasi masalah

Pada tahapan ini akan diperoleh berbagai masalah dari wilayah studi yang selanjutnya untuk mempermudah penyelesaian penelitian, dibuat perumusan masalah yang diambil dari batasan permasalahan yang akan diteliti.

2. Pengumpulan data

Pengumpulan data ini meliputi pengumpulan data sekunder yang diperoleh dari instansi terkait seperti Dinas Perhubungan Pememerintah Kabupaten Bekasi, Kepolisian RI atau Polres Bekasi, dan Ditjen Perhubungan Darat, sedangkan data primer diambil dari survei melalui pengisian kuisioner dan/atau wawancara langsung di lapangan terhadap pengemudi sepeda motor.

Setelah pengumpulan data baik primer maupun sekunder sudah dianggap lengkap dan valid, maka dilakukan analisis guna mendapatkan kondisi yang sebenarnya.

3. Keluaran (output)

Pada tahap ini merupakan tahap akhir yang meliputi tindak lanjut dari hasil analisis data, yang selanjutnya dituangkan dalam bentuk kesimpulan dan saran atau rekomendasi.

\section{B. Metode Pengumpulan Data}

Pengumpulan data meliputi pengumpulan data sekunder yang diperoleh dari instansi terkait seperti Dinas Perhubungan Pemerintah Kabupaten Bekasi dan Polres Bekasi, yang meliputi : 
1. Jumlah Sepeda Motor yang terdaftar di DKI Jakarta.

2. Jumlah Surat Izin Mengemudi (SIM) C Baru yang dikeluarkan Polres Bekasi.

3. Jumlah Sepeda Motor yang terlibat Kecelakaan Lalu Lintas di Kabupaten Bekasi.

4. Jumlah Korban Kecelakaan Lalu Lintas di Kabupaten Bekasi/DKI Jakarta.

Sedangkan data primer merupakan hasil survei yang akan dilakukan terhadap pengemudi sepeda motor, yang meliputi :

1. Kelaikan dan kelengkapan sepeda motor.

2. Perawatan sepeda motor.

3. Kelengkapan Administrasi dan kelengkapan bagi Pengemudi sepeda motor.

4. Angkutan dengan sepeda motor.

\section{Pelaksanaan Survei}

Survei dilakukan di satu tempat pada Jalan Kalimalang (Ruas Simpang Legenda Simpang Steger) dan Jalan Setu Raya (Ruas Simpang Steger - STTD) di Kabupaten Bekasi.

\section{Kerangka Pikir Penelitian}

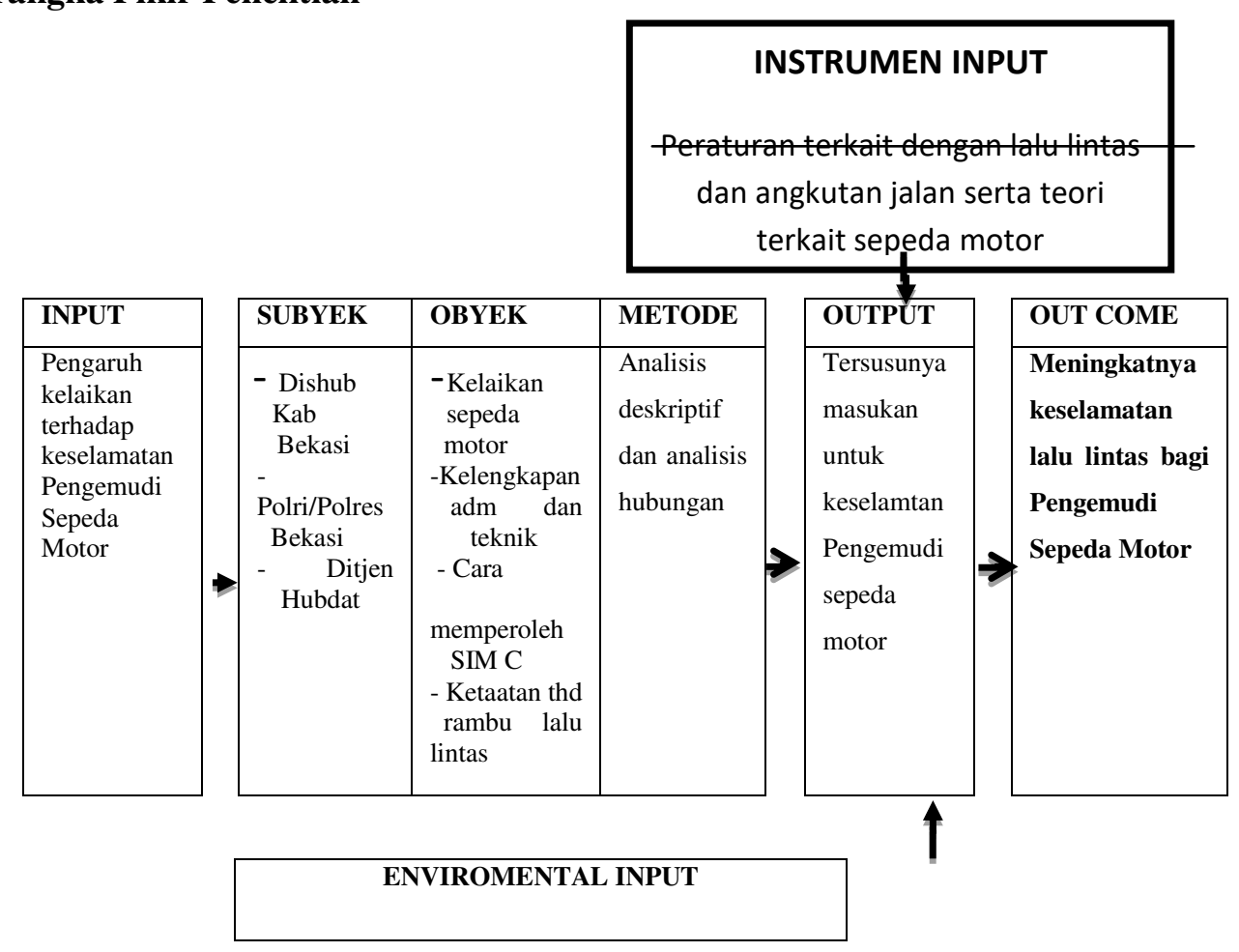

Gambar 3.1 Kerangka Pikir Penelitian

\section{E. Alur Pikir Penelitian}

Mulai 


\section{PEMBAHASAN DAN ANALISIS}

\section{A. Kelaikan dan Kelengkapan Teknis Sepeda Motor}

\section{Kondisi Ban}

Dari hasil survei yang dilakukan dengan jumlah responden sebanyak 200 orang, ternyata terdapat unsur kelaikan teknis sepeda motor berupa kondisi ban dengan baik sebanyak $172(86 \%)$ dan yang kondisi tidak baik sebanyak 28 (14\%), sebagaimana Tabel 5 dan

\section{Kondisi Rem}

Sedangkan untuk kondisi rem sepeda motor yang disurvei, dari jumlah responden sebanyak 200 orang, menunjukan 192 (96\%) dalam kondisi baik dan sebanyak 8 (4\%) menjujkan kondisi tidak baik, sebagaimana terlihat pada Tabel 6 dan Grafik 5.2 berikut.

\section{Kondisi Speedometer}

Untuk kondisi speedometer dari hasil survei dengan responden sebaynyak 200 orang, ternyata menunjukan sebayak 191 (95\%) dalam kondisi paik dan sebanyak 9 (5\%) menunjukan kondisi tidak baik, sebagaimana terlihat pada Tabel 7 dan Grafik 5.3 berikut ini.

\section{Kondisi Klakson}

Untuk kondisi klakson dari hasil survei dari responden sebanyak 200 orang, ternyata menunjukan sebayak 184 (92\%) dalam kondisi baik dan sebanyak 16 (8\%) menunjukan kondisi tidak baik, sebagaimana terlihat pada Tabel 8 dan Grafik 5.4 berikut ini.

\section{Kondisi Kaca Spion}

Untuk kondisi kaca spion dari hasil survei dengan responden sebanyak 200 orang, ternyata menunjukan sebayak 155 (77\%) dalam kondisi baik dan sebanyak 45 (23\%) menunjukan kondisi tidak baik, sebagaimana terlihat pada Tabel 9 dan Grafik 5.5 berikut ini.

\section{Kondisi Lampu Utama}

Untuk kondisi lampu utama dari hasil survei dengan responden sebanyak 200 orang, ternyata menunjukan sebayak 185 (92\%) dalam kondisi baik dan sebanyak 15 (8\%) menunjukan kondisi tidak baik, sebagaimana terlihat pada Tabel 10 dan Grafik 5.6 berikut ini

\section{Kondisi Lampu Sein}

Untuk kondisi lampu sein dari hasil survei dengan responden sebanyak 200 orang, ternyata menunjukan sebayak 185 (92\%) dalam kondisi baik dan sebanyak 15 (8\%) menunjukan kondisi tidak baik, sebagaimana terlihat pada Tabel 11 dan Grafik 5.7 berikut ini.

\section{Kondisi Lampu Belakang}


Untuk kondisi lampu belakang dari hasil survei dengan responden sebanyak 200 orang, ternyata menunjukan sebayak $185(92 \%)$ dalam kondisi baik dan sebanyak $15(8 \%)$ menunjukan kondisi tidak baik, sebagaimana terlihat pada Tabel 12 dan Grafik 5.8 berikut ini.

\section{Gambar Sepeda Motor yang tidak memenuhi persyaratan dan kelengkapan teknis}

Gambar-gambar berikut menunjukan sepeda motor yang tidak memenuhi persyaratan dan kelengkapan teknis.

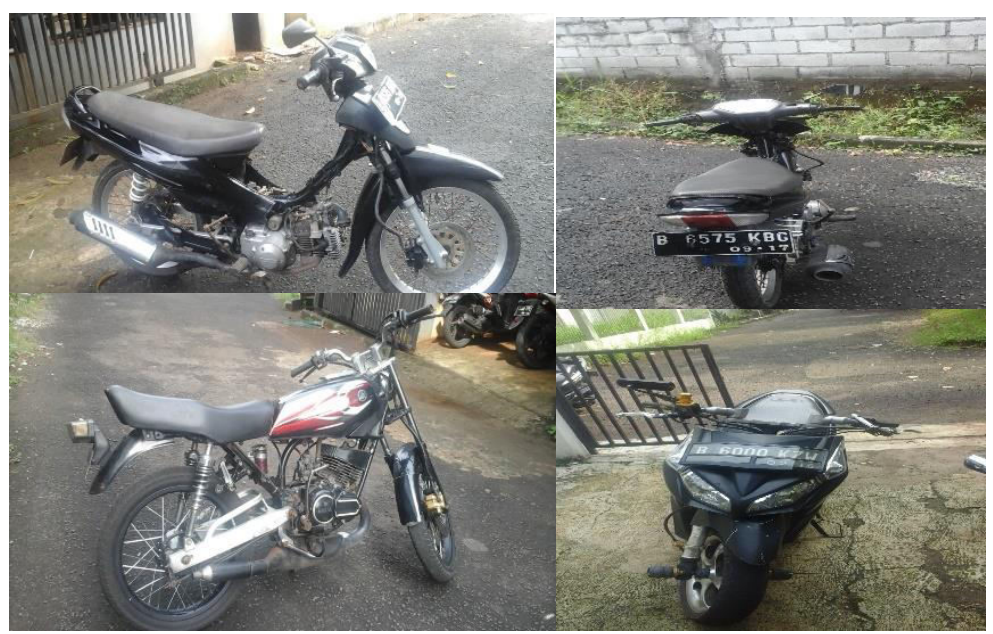

\section{B. Perawatan Sepeda Motor}

\section{Pemakaian sepeda motor}

Untuk pemakaian sepeda motor, dari hasil survei dengan responden sebanyak 200 orang, menunjukan sebayak 185 (92\%) pemakaian baru dan sebanyak $15(8 \%)$ menunjukan membeli sepeda motor bekas, sebagaimana terlihat pada Tabel 13 dan Grafik 5.14 berikut ini.

\section{Service Berkala 2.000 km/bulan}

Untuk service berkala sepeda motor $2.000 \mathrm{~km} /$ bulan, dari hasil survei dengan responden sebanyak 200 orang, menunjukan sebayak 172 (86\%) melakukan servise secara rutin dan sebanyak 28 (14\%) menunjukan tidak melakukan service secara rutin, sebagaimana terlihat pada Tabel 14 dan Grafik 5.15 berikut ini.

\section{Ganti Oli $2.000 \mathrm{Km} / \mathrm{bulan}$}

Untuk ganti oli secara berkala $2.000 \mathrm{~km} / \mathrm{bulan}$, dari hasil survei dengan responden sebanyak 200 orang, menunjukan sebayak 172 (86\%) mengganti secara rutin dan sebanyak 28 (14\%) menunjukan tidak mengganti secara rutin, sebagaimana terlihat pada Tabel 15 dan Grafik 5.16 berikut ini.

\section{Tindakan Terhadap Kerusakan}


Untuk tindakan terhadap kerusakan, dari hasil survei dengan responden sebanyak 200 orang, menunjukan sebayak 155 (77\%) merespon/mengganti dan sebanyak 45 (23\%) menunjukan menunggu jadwal service.

\section{Kelengkapan Administrasi dan Pengemudi Sepeda Motor Kepemilikan SIM}

Untuk kepemilikan SIM, dari hasil survei dengan responden sebanyak 200 orang, menunjukan sebayak 156 (78\%) memiliki dan sebanyak 44 (22\%) menunjukan tidak memiliki SIM, sebagaimana terlihat pada Tabel 17 dan Grafik 5.18 berikut ini.

\section{Kepemilikan STNK}

Untuk kepemilikan STNK, dari hasil survei dengan responden sebanyak 200 orang, menunjukan sebayak 186 (93\%) memiliki STNK dan sebanyak 14 (7\%) menunjukan tidak tidak memiliki STNK, sebagaimana terlihat pada Tabel 18 dan Grafik 5.19 berikut ini.

\section{Penggunaan Helm SNI}

Untuk penggunaan Hlm SNI, dari hasil survei dengan responden sebanyak 200 orang, menunjukan sebayak 193 (96\%) memiliki helm SNI dan sebanyak 7 (4\%) menunjukan tidak memiliki helm SNI, sebagaimana terlihat pada Tabel 19 dan Grafik 5.20 berikut ini.

\section{Penggunaan Jaket/Rompi}

Untuk penggunaan jaket/rompi, dari hasil survei dengan responden sebanyak 200 orang, menunjukan sebayak 81 (60\%) menggunakan jaket/rompi warna terang dan sebanyak 119 (60\%) menunjukan tidak menggunakan, sebagaimana terlihat pada Tabel 20 dan Grafik 5.21 berikut ini.

\section{Penggunaan Sepatu}

Untuk penggunaan sepatu, dari hasil survei dengan responden sebanyak 200 orang, menunjukan sebayak $164(82 \%)$ menggunakan dan sebanyak $36(18 \%)$ menunjukan tidak menggunakan.

\section{Penggunaan Sarung Tangan}

Untuk penggunaan sarung tangan, dari hasil survei dengan responden sebanyak 200 orang, menunjukan sebayak 100 (50\%) menggunakan sarung tangan dan sebanyak 100 $(50 \%)$ menunjukan tidak menggunakan sarung tangan, sebagaimana terlihat pada Tabel 22 dan Grafik 5.23 berikut ini.

\section{Angkutan dengan Sepeda Motor}

\section{Penumpang Lebih dari 2 orang}

Untuk mengangkut penumpang lebih dari 2 orang, dari hasil survei dengan responden sebanyak 200 orang, menunjukan sebayak 160 (80\%) tidak pernah 
mengangkut penumpang lebih dari 2 orang dan sebanyak 40 (20\%) menunjukan pernah mengangkut penumpang lebih dari 2 orang, sebagaimana terlihat pada Tabel 23 dan Grafik 5.24 berikut ini.

\section{Barang}

Untuk mengangkut barang dengan pengepakan, dari hasil survei dengan responden sebanyak 200 orang, menunjukan sebayak 53 (26\%) pengepakan dengan baik dan sebanyak 147 (74\%) menunjukan pengepakan tidak baik, sebagaimana terlihat pada Tabel 24 dan Grafik 5.25 berikut ini.

Sebagai rangkuman dari hasil survei mengenai kondisi kelaikan dan kelengkapan teknis sepeda motor, perawatan sepeda motor, dan kelengkapan administrasi dan pengemudi sepeda motor, serta angkutan dengan sepeda motor, sebagaimana terlihat pada Tabel 25, Tabel 26, Tabel 27, dan Tabel 28 berikut ini.

\section{HASIL SURVEI KONDISI KELAIKAN DAN KELENGKAPAN TEKNIS SEPEDA MOTOR}

(Responden 200 orang)

\begin{tabular}{|l|l|l|l|}
\hline No. & Elemen Kelaikan dan elengkapan Teknis & Baik $(\%)$ & Tidak Baik (\%) \\
\hline 1. & Ban & $172(86 \%)$ & $28(14 \%)$ \\
\hline 2. & Rem & $192(96 \%)$ & $8(4 \%)$ \\
\hline 3. & Speedo meter & $191(95 \%)$ & $9(5 \%)$ \\
\hline 4. & Klakson & $184(92 \%)$ & $16(8 \%)$ \\
\hline 5. & Kaca Spion & $155(77 \%)$ & $45(23 \%)$ \\
\hline 6. & Lampu Utama & $185(92 \%)$ & $15(8 \%)$ \\
\hline 7. & Lampu Sein & $185(92 \%)$ & $15(8 \%)$ \\
\hline
\end{tabular}

\section{HASIL SURVEI PERAWATAN SEPEDA MOTOR}

\section{(Responden 200 orang)}

\begin{tabular}{|l|l|l|l|}
\hline No. & Elemen & Baru (\%) & Bekas (\%) \\
\hline 1. & Pemakaian Sepeda Motor & $185(92 \%)$ & $15(8 \%)$ \\
\hline & & Rutin (\%) & Tidak Rutin (\%) \\
\hline 2. & Service $2.000 \mathrm{~km}$ & $172(86 \%)$ & $28(14 \%)$ \\
\hline 3. & Ganti Oli $2.000 \mathrm{~km}$ & $172(86 \%)$ & $28(14 \%)$ \\
\hline & & Mengganti (\%) & Bersamaan Service \\
\hline
\end{tabular}




\begin{tabular}{|l|l|l|l|}
\hline 4. & Tindakan terhadap kerusakan & $155(77 \%)$ & $45(23 \%)$ \\
\hline
\end{tabular}

\section{HASIL SURVEI KELENGKAPAN ADMINISTRASI DAN PENGEMUDI SEPEDA}

\section{MOTOR}

(Responden 200 orang)

\begin{tabular}{|l|l|l|l|}
\hline No. & Elemen & Memiliki/memakai $(\boldsymbol{\%})$ & $\begin{array}{l}\text { Tidak memiliki/memakai } \\
(\boldsymbol{\%})\end{array}$ \\
\hline 1. & SIM & $156(78 \%)$ & $44(22 \%)$ \\
\hline 2. & STNK & $186(93 \%)$ & $14(7 \%)$ \\
\hline 3. & Helm SNI & $193(96 \%)$ & $7(4 \%)$ \\
\hline 4. & Jaket/Rompi & $81(40 \%)$ & $119(60 \%)$ \\
\hline 5. & Sepatu & $164(82 \%)$ & $36(18 \%)$ \\
\hline 6. & Sarung tangan & $100(50 \%)$ & $100(50 \%)$ \\
\hline
\end{tabular}

\section{HASIL SURVEI ANGKUTAN DENGAN SEPEDA MOTOR}

(Responden 200 orang)

\begin{tabular}{|l|l|l|l|}
\hline No. & Elemen & $\begin{array}{l}\text { Pernah/pengepakan baik } \\
(\%)\end{array}$ & $\begin{array}{l}\text { Tidak pernah/pengepakan } \\
\text { tidak bai (\%) }\end{array}$ \\
\hline 1. & $\begin{array}{l}\text { Penumpang lebih } \\
2 \text { orang }\end{array}$ & $160(80 \%)$ & $40(20 \%)$ \\
\hline 2. & Barang & $53(26 \%)$ & $147(74 \%)$ \\
\hline
\end{tabular}

E. Analisis Regresi Tingkat Keselamatan dengan Persyaratan Teknis dan Persyaratan Administrasi Sepeda Motor

HUBUNGAN VARIABEL PERSYARATAN TEKNIS DAN ADMINISTRASI DENGAN KESELAMATAN

\begin{tabular}{|c|c|c|c|c|}
\hline \multicolumn{5}{|c|}{ Correlations } \\
\hline & & $\begin{array}{l}\text { SYARAT } \\
\text { TEKNNIS }\end{array}$ & $\begin{array}{l}\text { SYARAT } \\
\text { ADMINISTRA } \\
\text { S| }\end{array}$ & $\begin{array}{l}\text { TINGKAT } \\
\text { KESELAMATA } \\
N\end{array}$ \\
\hline \multirow[t]{3}{*}{ SYARAT_TEKNIS } & Pearson Correlation & 1 & .111 & $.888^{\prime \prime}$ \\
\hline & Sig. (2-tailed) & & .118 & .000 \\
\hline & N & 200 & 200 & 200 \\
\hline \multirow[t]{3}{*}{ SYARAT_ADMMNNISTRASI } & Pearson Correlation & .111 & 1 & $.344^{\prime \prime}$ \\
\hline & Sig. (2-tailed) & .118 & & .000 \\
\hline & N & 200 & 200 & 200 \\
\hline \multirow[t]{3}{*}{ TINGKAT_KESELAMATAN } & Pearson Correlation & $.888^{\prime \prime}$ & .344" & 1 \\
\hline & Sig. (2-tailed) & .000 & .000 & \\
\hline & $\mathrm{N}$ & 200 & 200 & 200 \\
\hline
\end{tabular}

*. Correlation is significant at the 0.01 level (2-tailed). 
Dari tabel diatas Korelasi Antar Variable tersebut di atas, dapat dilihat bahwa, variabel persyaratan teknis dan persyaratan administrasi tidak saling mempengaruhi, sehingga model dapat digunakan. Sedangkan Variabel Tingkat Keselamatan memiliki keterkaitan yang cukup kuat dengan variabel persyaratan administrasi dan persyaratan teknis. Hal ini ditunjukan dengan hubungan tingkat keselamatan dengan persyaratan teknis sebesar 0.888 dan hubungan tingkat keselamatan dengan persyaratan administrasi 0.344 .

Model Summary

\begin{tabular}{|c|c|c|c|c|}
\hline Mode & $\mathrm{R}$ & RS Square & $\begin{array}{c}\text { Adjusted R } \\
\text { Square } \\
\end{array}$ & $\begin{array}{l}\text { Std. Error of } \\
\text { the Estimate }\end{array}$ \\
\hline 1 & $.888^{2}$ & .789 & .788 & .14785 \\
\hline 2 & $.922^{\mathrm{b}}$ & .850 & .849 & 12492 \\
\hline
\end{tabular}

Seperti yang terlihat dalam Tabel 30. Model Summary di atas, nilai pada kolom R adalah 0,850 artinya pengaruh variabel persyaratan teknis dan persyaratan administrasi terhadap tingkat keselamatan adalah $85,0 \%(0,850 \times 100 \%)$, namun nilai tersebut dapat dikatakan "terkontaminasi" oleh berbagai nilai pengganggu yang mungkin menyebabkan kesalahan pengukuran. Untuk itu alternatif nilai $\mathrm{R}$ Square sebagai perbandingan akurasi pengaruhnya.

Terlihat bahwa nilai R Square sebesar 0,849 yang artinya 84,9\%. Nilai ini lebih kecil dari nilai $\mathrm{R}$ akibat adanya penyesuaian. Untuk lebih akuratnya prediksi pengaruhnya, juga dapat berpatokan pada nilai Adjusted $R$ Square, yaitu nilai R Square tadi yang sudah lebih disesuaikan dan lazimnya ini yang paling akurat. Terlihat bahwa nilai Adjusted $R$ Square-nya sebesar 0,849 atau $84,9 \%$ pengaruh variabel independen terhadap variabel dependen.

Pada Model Summary tersebut, memperlihatkan tingkat keakuratan model regresi dapat dilihat pada kolom Standard Error of The Estimate, di sana tertera angka 0.12492. Nilai ini semakin mendekati angka 0 (nol), sehingga semakin akurat, dengan angka sebesar itu maka dapat dikatakan model yang terbentuk akurat. 
ANOVA $^{\mathrm{C}}$

\begin{tabular}{|ll|r|r|r|r|r|}
\hline Moded & & \multicolumn{1}{c|}{$\begin{array}{c}\text { Sum of } \\
\text { Squares }\end{array}$} & \multicolumn{1}{c|}{ df } & Mean Square & F & Sig. \\
\hline 1 & Regression & 16.206 & 1 & 16.206 & 741.329 & $.000^{\circ}$ \\
& Residual & 4.328 & 198 & .022 & & \\
& Total & 20.535 & 199 & & & \\
\hline 2 & Regression & 17.460 & 2 & 8.730 & 559.419 & $.000^{\circ}$ \\
& Residual & 3.074 & 197 & .016 & & \\
& Total & 20.535 & 199 & & & \\
\hline
\end{tabular}

a. Predictors: (Constant), SYARAT_TEKNNS

b. Predictors: (Constant), SYARAT_TEKNNS, SYARAT_ADMNNNISTRASI

c. DependentVariable: TINGKAT_KESELAMATAN

Dalam tabel Uji Anova tersebut di atas, memperlihatkan informasi tentang berpengaruh tidaknya variabel independen terhadap variabel dependen secara simultan (bersamasama).

Pada Uji Anova tersebut, nilai sig. tertera sebesar 0,000 maka dapat disimpulkan bahwa variabel integritas keselamatan, kompetensi faktor keselamatan dan indpendensi elemen keselamatan, berpengaruh secara bersama-sama terhadap kualitas keselamatan. Hal ini dengan mengikuti taraf sig. 0,05 sebagai nilai cut off dari nilai signifikansi. Artinya jika nilai probabilitas (signifikansi) di bawah 0,05 maka seluruh variabel independen berpengaruh terhadap variabel dependen dan begitupun sebaliknya.

Coefficients

\begin{tabular}{|c|c|c|c|c|c|c|}
\hline \multirow[b]{2}{*}{ Model } & & \multicolumn{2}{|c|}{ Unstandardized Coefficients } & \multirow{2}{*}{$\begin{array}{c}\text { Standardized } \\
\text { Coefficients }\end{array}$} & \multirow[b]{2}{*}{1} & \multirow[b]{2}{*}{ Sig. } \\
\hline & & B & Std. Error & & & \\
\hline 1 & (Constant) & .3 .858 & .201 & & .19 .207 & .000 \\
\hline & SYARAT_TEKN NS & 166 & .006 & .888 & 27.227 & 000 \\
\hline 2 & (Constant) & -4.280 & .176 & & -24.301 & .000 \\
\hline & SYARAT_TEKN NS & .161 & .005 & .861 & 31.033 & .000 \\
\hline & SYARAT_ADMNNISTRASI & .159 & 018 & .249 & 8.965 & .000 \\
\hline
\end{tabular}

a. DependentVariable: TINGKAT_KESELAMATAN

Pada Tabel Coeficıent tersebut aı atas, aısajıkan perbagaı intorması pentıng terdiri atas nama-nama variabel, nilai kostanta (Constant), nilai t dan nilai signifikansi.

Secara Signifikan X1 dan X2 mempengaruhi variabel terikat (Y), dengan dibuktikan oleh nilai signifikasi sebesar kurang dari 0.05

Dengan persamaan $=\mathrm{a}+\mathrm{Bx} 1+\mathrm{Bx} 2$

Keselamatan mempunyai persamaan $\mathrm{Y}=-4.280+0.161 . \mathrm{X} 1+0.158 \mathrm{X} 2$ 


\section{KESIMPULAN DAN SARAN}

\section{A. Kesimpulan}

Dari uraian dalam Bab-bab terdahulu dapat diambil kesimpulan sebagai berikut :

1. Keselamatan sangat terkait dengan faktor persyaratan dan kelengkapan teknis sepeda motor (laik jalan) serta faktor persyaratan administrasi dan kelengkapan pengemudi sepeda motor.

2. Pengaruh faktor persyaratan dan kelengkapan teknis sepeda motor serta faktor persyaratan administrasi dan kelengkapan pengemudi sepeda motor dengan keselamatan sangat besar, namun masih terdapat faktor lain yang mempengaruhi (faktor prasarana, manusia dan lingkungan).

3. Untuk mengemudikan sepeda motor yang selamat antara lain harus :
a. mengemudikan kendaraannya dengan wajar dan penuh konsentrasi;
b. mengutamakan keselamatan pejalan kaki dan pesepeda;
c. mematuhi ketentuan tentang persyaratan teknis dan laik jalan;
d. mematuhi ketentuan mengenai :

1) rambu perintah atau rambu larangan;

2) marka jalan;

3) alat pemberi isyarat lalu lintas;

4) gerakan lalu lintas;

5) berhenti dan parkir;

6) peringatan dengan bunyi dan sinar;

7) kecepatan maksimal atau minimal.

\section{B. Saran-saran}

Terhadap kesimpulan tersebut di atas dapat diberikan saran sebagai berikut :

1. Perlu terus dilakukan sosialisasi terhadap peraturan tentang persyaratan laik jalan sepeda motor dan persyaratan administrasi dan kelengkapan Pengemudi sepeda motor.

2. Di samping faktor laik jalan dan persyaratan administrasi dan kelengkapan Pengemudi sepeda motor, perlu diperhatikan pula faktor lain yang mempengaruhi keselamatan, yaitu prasarana, manusia, dan lingkungan.

3. Tata cara mengemudikan sepeda motor perlu terus disosialisasikan kepada masyarakat pada umumnya dan para pelajar pada khususnya. 


\section{DAFTAR PUSTAKA}

Jalius Jama, Prof, Dr, M.Ed, dkk, Buku Teknik Sepeda Motor Mobile-Friedly, Penerbit Pusat Perbukuan Departemen Pendidikan Nasional, Jakarta,2008.

Sutiman dan Moch. Solihin, Buku Mesin Sepeda Motor, Penerbit UNY, Jakarta.

Spyros et al, Metode dan Aplikasi Peramalan, Edisi Kedua (diterjemahkan oleh Untung S. Andriyanto dan Abdul Basith), Penerbit Erlangga, Jakarta, 1983.

Kabupaten Bekasi Dalam Angka 2013, Bekasi, 2013.

BPS Provinsi DKI Jakarta, Statistik Transportasi DKI Jakarta 2015, Jakarta, 2015

Direktorat Jenderal Perhubungan Darat, Departemen Perhubungan, 2009, Undang-undang Republik Indonesia No. 22 Tahun 2009 Tentang Lalu lintas dan Angkutan Jalan, Jakarta.

Direktorat Jenderal Perhubungan Darat, Kementerian Perhubungan, 2012, Peraturan Pemeritah Republik Indonesia Nomor 55 Tahun 2012 Tentang Kendaraan, Jakarta.

Direktorat Jenderal Perhubungan Darat, Kementerian Perhubungan, 2014, Peraturan Pemeritah Republik Indonesia Nomor 74 Tahun 2014 Tentang Angkutan Jalan, Jakarta.

Pusat Penelitian dan Pengabdian Masyarakat, Sekolah Tinggi Transportasi Darat, Buku Pedoman Berlalu Lintas 2015, Bekasi. 